\title{
Erratum to: Endoscopic transluminal necrosectomy in necrotising pancreatitis: a systematic review
}

\author{
Sandra van Brunschot • Paul Fockens · Olaf J. Bakker • Marc G. Besselink • \\ Rogier P. Voermans $\cdot$ Jan-Werner Poley $\cdot$ Hein G. Gooszen $\cdot$ Marco Bruno • \\ Hjalmar C. van Santvoort
}

Published online: 2 May 2014

(C) Springer Science+Business Media New York 2014

\section{Erratum to: Surg Endosc}

DOI 10.1007/s00464-013-3382-9

The affiliations appear correct as listed in this erratum.

The online version of the original article can be found under doi: 10 . 1007/s00464-013-3382-9.

S. van Brunschot $(\bowtie) \cdot H$. G. Gooszen

Department of OR/Clinical Surgical Research, Radboud

University Nijmegen Medical Center, Nijmegen, The

Netherlands

e-mail: s.vanbrunschot@pancreatitis.nl

S. van Brunschot · P. Fockens - R. P. Voermans

Department of Gastroenterology and Hepatology, Academic

Medical Center, Amsterdam, The Netherlands

O. J. Bakker · H. C. van Santvoort

Department of Surgery, University Medical Center Utrecht, Utrecht, The Netherlands

e-mail: h.vansantvoort@pancreatitis.nl

M. G. Besselink

Department of Surgery, Academic Medical Center, Amsterdam,

The Netherlands

J.-W. Poley · M. Bruno

Department of Gastroenterology and Hepatology, Erasmus MC,

University Medical Center, Rotterdam, The Netherlands 